\title{
(6) \\ Effect on secondary care of OPEN ACCESS providing enhanced support to residential and nursing home residents: a subgroup analysis of a retrospective matched cohort study
}

\author{
Therese Lloyd, ${ }^{1}$ Stefano Conti, ${ }^{2}$ Filipe Santos, ${ }^{2}$ Adam Steventon ${ }^{3}$
}

- Additional material is published online only. To view please visit the journal online (http://dx.doi.org/10.1136/ bmjqs-2018-009130).

${ }^{1}$ Improvement Analytics Unit, The Health Foundation, London, UK

${ }^{2}$ Improvement Analytics Unit and Data, Analysis and Intelligence Services, NHS England, London, UK ${ }^{3}$ Data Analytics, The Health Foundation, London, UK

\section{Correspondence to}

Therese Lloyd, Improvement Analytics Unit, The Health Foundation, London WC2E 9RA, UK; therese.lloyd@health.org.uk

Received 22 November 2018 Revised 5 February 2019 Accepted 1 March 2019 Published Online First 7 April 2019

\section{SLinked}

- http://dx.doi.org/10.1136/ bmjqs-2019-009384

- http://dx.doi.org/10.1136/ bmjqs-2019-009447

- http://dx.doi.org/10.1136/ bmjqs-2018-008924

\section{Check for updates}

(C) Author(s) (or their employer(s)) 2019. Re-use permitted under CC BY-NC. No commercial re-use. See rights and permissions. Published by BMJ.

To cite: Lloyd T, Conti S, Santos F, et al. BMJ Qual Saf 2019;28:534-546.

\begin{abstract}
Background Thirteen residential care homes and 10 nursing homes specialising in older people in Rushcliffe, England, participated in an improvement programme. The enhanced support provided included regular visits from named general practitioners and additional training for care home staff. We assessed and compared the effect on hospital use for residents in residential and nursing homes, respectively.

Methods Using linked care home and administrative hospital data, we examined people aged 65 years or over who moved to a participating care home between 2014 and $2016(n=568)$. We selected matched control residents who had similar characteristics to the residents receiving enhanced support and moved to similar care homes not participating in the enhanced support $(n=568)$. Differences in hospital use were assessed for residents of each type of care home using multivariable regression.

Results Residents of participating residential care homes showed lower rates of potentially avoidable emergency admissions (rate ratio $0.50,95 \% \mathrm{Cl} 0.30$ to 0.82 ), emergency admissions (rate ratio $0.60,95 \% \mathrm{Cl}$ 0.42 to 0.86 ) and Accident \& Emergency attendances $(0.57,95 \% \mathrm{Cl} 0.40$ to 0.81$)$ than matched controls. Hospital bed days, outpatient attendances and the proportion of deaths that occurred out of hospital were not statistically different. For nursing home residents, there were no significant differences for any outcome. Conclusions The enhanced support was associated with lower emergency hospital use for older people living in residential care homes but not for people living in nursing homes. This might be because there was more potential to reduce emergency care for people in residential care homes. In nursing homes, improvement programmes may need to be more tailored to residents' needs or the context of providing care in that setting.
\end{abstract}

\section{INTRODUCTION}

As of 2016/17, approximately 420000 people aged 65 years or over live in care homes across the UK. ${ }^{1}$ Care homes offer accommodation and personal care (such as help with washing, dressing and taking medicines) to residents 24 hours a day; if they also provide 24 hours' access to a qualified nurse they are known as nursing homes, otherwise they are residential care homes. ${ }^{2}$ Older people living in care homes increasingly have complex health and care needs, including dementia, progressive frailty and need for end-of-life care. ${ }^{3-9}$ Caring for older care home residents is a key priority for the health and care system in England, ${ }^{10-12}$ as in many other countries, yet the quality of care received varies between care homes. ${ }^{13-18}$

Following the National Health Service (NHS) Five Year Forward View in England, ${ }^{19}$ New Care Models vanguards were established, including six Enhanced Health in Care Homes (EHCH) pilots in 2015. The $\mathrm{EHCH}$ framework aimed to offer older people living in care homes better, joined-up health, care and rehabilitation services. ${ }^{20}$ A key measure for success of the pilots was reduced emergency hospital use, ${ }^{3} 20$ since emergency admissions can be detrimental to older people's health and well-being, ${ }^{21} 22$ exposing them to stress and risk of infection, ${ }^{23}$ as well as being costly to the NHS. Although emergency admissions are often necessary, ${ }^{24}$ many emergency admissions may be avoidable and could have been managed outside of a hospital setting. ${ }^{21}{ }^{25-28}$ Overall, aggregate figures of $\mathrm{EHCH}$ vanguards indicate that emergency admission rates from participating care homes remained broadly stable between 2014/2015 and 2017/2018, compared with higher rising rates for non-vanguard care homes over the same period. ${ }^{29}$ There is likely to be substantial variation within this picture, and a need 
to identify which elements of the interventions can reduce emergency admissions, for whom and in which contexts. This is particularly relevant as the NHS announced in January 2019 its 10-year Long Term Plan, which commits to improving NHS support to all care homes, including stronger links between care homes and primary care services and more support by a consistent team of health professionals. This includes rolling out the EHCH model ${ }^{20}$ across all of England. ${ }^{12}$

There is little research into which interventions improve care and reduce hospital admissions from care homes; moreover, the available evidence is often of low quality. ${ }^{30-32}$ The evidence on reducing emergency admissions is mixed. ${ }^{3} 293033-47$ However, our recent evaluation of an enhanced support package in Rushcliffe, which included regular visits from named general practitioners (GP) and additional training for care home staff, showed that older people moving to participating care homes had significantly lower rates of Accident \& Emergency (A\&E) attendances and emergency admissions than a matched control group. ${ }^{35}$ Looking more broadly at the body of evidence on improving care in care homes, there is promising evidence emerging. ${ }^{32}$ For example, there are indications that training and support can lead to changes in staff priorities and practices. ${ }^{48}$ There are several themes emerging, often in combination: multidisciplinary, partnership working and good working relationships between care home staff, GPs and other healthcare professionals 3153132 40-42 44-47 49-54; training for care home staff ${ }^{15} 31344041454748515255-57$; the use of data for monitoring residents' outcomes ${ }^{43}$ 47-49 53; better preventative assessment and care management ${ }^{404953}$; advance care planning ${ }^{4041465356}$; end-of-life care planning ${ }^{313241495357}$; and medicines management. ${ }^{32} 344250$

Although residential and nursing homes may differ in both context (eg, nursing provision) and resident characteristics, ${ }^{58-60}$ there is, to our knowledge, no research into understanding how these differences may affect the outcomes of improvement programmes in care homes. The vast majority of studies either do not distinguish between residential and nursing homes or evaluate only one care home type. Furthermore, differences in interventions and study design make any patterns in study results between care home types difficult to discern.

There is, however, some evidence of variability between residential and nursing homes. ${ }^{16}$ For example, medication administration errors may be less likely among nursing homes. ${ }^{61}$ Residential care home residents may have higher ambulance call rates $^{62}$ and higher emergency admission rates ${ }^{63}$ than nursing home residents. There are indications that GPs visit nursing home more regularly than residential care homes ${ }^{43} 64$ and that nursing homes are more likely than residential care homes to have an aligned general practice and to pay a general practice to provide services, ${ }^{65}$ even though residential care home residents may also have needs requiring healthcare support. ${ }^{435}$

The current study expands on the previous evaluation of the Principia enhanced support in Rushcliffe by examining the effect on hospital use in residential and nursing homes separately, and assessing whether the effect differed between care home types. Such information might inform both NHS England and healthcare teams looking to make improvements in care homes. Our analysis was specified a priori in the statistical analysis protocol written for the original evaluation ${ }^{66}$ and is based on the same study period as that evaluation.

\section{METHODS}

\section{The enhanced support intervention}

The enhanced support was introduced in April 2014 for all care homes in Rushcliffe that care specifically for older residents, as well as two additional care homes in the nearby vicinity (14 residential and 10 nursing homes in total). It was developed by Principia, a local partnership of GPs, patients and community services, together with care home managers and the Rushcliffe Clinical Commissioning Group (CCG) lead. Principia became a Multidisciplinary Community Provider New Care Model vanguard in 2015.

Although the enhanced support was introduced before the $\mathrm{EHCH}$ vanguards, it shares elements of the $\mathrm{EHCH}$ model $^{20}$ and our earlier evaluation was quoted in the Long Term Plan as an example of a successful implementation of the model. ${ }^{12}$ During the period of our study (17 August 2014 to 14 August 2016), the enhanced support consisted of four components.

1. Each care home was aligned with a general practice, which care home residents within the home were encouraged to register with, though this was not compulsory. Within each practice there was one named GP who visited the home on a regular (weekly or fortnightly) basis, meeting with those residents who were registered with the general practice as needed and proactively reviewing their medications and care plans. This ensured continuity of care for the residents and the development of personal relationships between the GP and both residents and staff. There was also a deputy GP who would step in if the regular named GP was absent. Needs were identified and discussed during the ward rounds. New residents were reviewed, including having comprehensive geriatric assessments. Principia estimated that approximately $90 \%$ of residents were registered with the aligned GP.

2. A programme of work engaging care home managers aimed to improve relationships between care providers working in different settings, promoting shared ownership and consistency of approach. This included a care home managers' network that met bimonthly and a monthly task group meeting between representatives of all members of the team.

3. The charitable organisation Age UK Nottingham and Nottinghamshire aimed to supply independent infor- 
mation to residents and their families to inform their decision about whether to change to the aligned local general practice after moving to the care home and, more generally, provide a safe and trusted point of contact for residents. Age UK Nottingham and Nottinghamshire also facilitated the care home managers' network.

4. Community nurses provided training to care home staff on an ad hoc basis, for example, following staff changes, changes to guidelines, requests from care managers or staff, or when community nurses or GPs identified a need. Training was provided on, for example, falls, heart failure, palliative care, wound care, catheter care, sepsis training and pressure sore management. Community nurses were not formally instructed in how to deliver this training but standardised slides were used for training purposes. They referred to or provided information on existing specialist community services; offered peerto-peer support to nurses in nursing homes; and accompanied GPs on the regular resident review rounds in residential care homes. There were three teams of community nurses in Rushcliffe, each with responsibility for a group of care homes, thereby ensuring continuity of care for residents.

All four components were implemented in both residential and nursing homes, though with some differences. The training and support element (4) was delivered to all healthcare assistants in both nursing and residential care homes, but was optional for nurses in nursing homes. An important distinction was that community nurses typically attend nursing homes less frequently than residential care homes, since nursing homes employ their own nurses. Therefore, there were fewer opportunities for community nurses to recognise demand for training or share information and good practice in nursing homes than in residential care homes. However, a community nurse with a special interest in palliative care visited both residential and nursing homes regularly, providing end-of-life training, including pain management. Falls specialists delivered training to staff in both types of care home, including nurses, carers, administrative staff, ancillary staff and kitchen staff. Community nurses provided peer-to-peer nurse support in nursing homes only. In residential homes, the GP was accompanied on the ward rounds by a community nurse and either the care home manager or senior carer; in nursing homes, they were accompanied by an in-house nurse or the care home manager.

\section{Study outcomes}

The enhanced support aimed to improve residents' care, involvement in decisions about their care and quality of life. Consistent with the overall aims of the $\mathrm{EHCH}$ vanguards, there were specific objectives to reduce secondary care use, including A\&E attendances and emergency admissions.

The primary outcome of interest for our study was potentially avoidable emergency admissions, identified based on the primary diagnosis recorded in hospital administrative data. These were unplanned admissions for conditions that were potentially manageable, treatable or preventable outside of a hospital setting, or for conditions that could be caused by poor care or neglect. ${ }^{6768}$ The list of conditions was developed by the Care Quality Commission (CQC) as part of their analysis on older people experiencing health and social care. Conditions included acute and chronic lower respiratory tract infections, decubitus ulcers (pressure sores), diabetes, food and drink issues, food and liquid pneumonitis, fractures and sprains, intestinal infections, pneumonia and urinary tract infections. For example, some fractures may be avoidable with appropriate risk assessment and falls prevention and urinary tract infections may be treatable within the community or care home. However, context is also a factor in determining whether a 'potentially avoidable' admission could in fact have been avoided. For example, if a residential care home resident had pneumonia, hospital admission may be the most effective way of eliminating the infection quickly, whereas the available nursing support in a nursing home may have been able to oversee treatment of the same condition within the nursing home. Admissions for these conditions cannot always be avoided. However, the enhanced support available in care homes could be expected to have greater impact on admissions for these conditions than others.

Other outcomes were emergency admissions (defined as any admission to hospital that was urgent and unexpected, that is, unplanned, and occurring either via A\&E departments or directly via GPs or consultants in ambulatory clinics); A\&E attendances (regardless of whether the person was subsequently admitted); number of hospital bed days (calculated as number of nights during which a resident was a hospital inpatient following emergency or elective admission); and attendances at outpatient departments (excluding instances where the patient did not attend a booked appointment). Furthermore, we analysed the proportion of deaths outside of hospital. This was a proxy for residents dying in their place of choice. Although we considered the number of elective admissions, results are not presented here due to the small number of events in the residential and nursing subgroups.

Hospital use was measured over the period during which individuals were resident in a care home, beginning from the month of moving into the home and ending in the month of moving out or death (or the end of our study period on 14 August 2016 if earlier). Outcomes were therefore measured over a maximum of 23 months, but over varying study durations for each resident depending on when they lived in the care home. 


\section{Data sources and linkage}

We used pseudonymised administrative data from the Secondary Uses Service (SUS), a national database of all inpatient admissions, A\&E attendances and outpatient appointments funded by the NHS in England. One challenge for our study was that SUS data do not accurately record whether an individual lives in a care home. We therefore identified residents of care homes from the National Health Applications and Infrastructure Services (NHAIS) database, which contains information on all registrations with general practices in England, including each patient's residential address and death information. From NHAIS, we received pseudonymised extracts for each month between August 2014 and August 2016 (with each extract created at 06:00 on the first Sunday after the 13 th of each month). From these NHAIS extracts, we extracted a list of unique address fields for people aged 65 or over living at a care home postcode within the geographical areas of interest. These were isolated from any identifiable data and manually cross-referenced with the addresses of care homes registered with CQC, the health and social care service regulator in England, within a secure data environment. This information was then used by the Arden \& Greater East Midlands Data Services for Commissioners Regional Office to create a pseudonymised database containing every care home stay that began between 17 August 2014 at 06:00 and 17 July 2016 at 06:00 and including the dates of the care home stay, date of death (where applicable) and some limited information about each care home, such as care home type and number of beds, derived from CQC data. The pseudonymised database of care home stays was then linked to the SUS data. In this way, we were able to identify care home residents more precisely than we could from SUS data alone.

\section{Study populations}

In order to create a 'pool' of potential control residents from which the matched controls could be drawn, ${ }^{69}$ we selected six local authorities in England that were similar to Rushcliffe in terms of demographics, socioeconomic characteristics and age standardised emergency admission rates in the period prior to the introduction of the enhanced support. ${ }^{70}$ The process was based on the method applied by the Office for National Statistics ${ }^{7172}$ to determine comparable health areas in England. Any local authorities with area-wide interventions relating to care homes deemed untypical of usual care that we were aware of were excluded from the list, including EHCH vanguard sites. ${ }^{320}$ The final list of six comparison areas were Harborough, Blaby, Test Valley, South Cambridgeshire, Chelmsford and Brentwood.

Care homes were considered for inclusion in the study if they cared for adults over 65 years (according to care home criteria defined by CQC), ${ }^{73}$ and either offered the enhanced support or were located in one of the six comparison areas. However, one Principia care home was excluded as only around half of its residents received enhanced support under a Principia-led general practice, thus leaving 23 care homes for older people in the Principia group.

Residents were considered for inclusion in the study if they moved into one of the care homes between 17 August 2014 and 17 July 2016 when aged 65 or over. Residents who moved in earlier were excluded, as hospital activity is likely to differ depending on whether a person lives at home or in a care home and may also change depending on length of time spent in a care home. As NHAIS extracts before August 2014 were unavailable, it was not possible to determine move-in dates prior to that and therefore to match reliably on prior hospital use. As the enhanced support was introduced in April 2014, this allowed in effect for a 'bedding-in' period for the care homes of approximately 5 months. We excluded residents without a record of prior inpatient admission in the 2 years before moving to the care home, as prior hospital data were required to define certain baseline resident characteristics such as health conditions. People who were known to have previously lived in a care home (whether in Rushcliffe or in a comparison area) were also excluded.

The residential and nursing home subgroups were determined by information provided from the CQC database. Some care homes are 'dual registered', that is, provide care both with and without nursing but the CQC database lists these as 'nursing homes'; therefore, the nursing home population in this study will include some residents receiving only residential care. Online supplementary file 1 displays a flow diagram with details of inclusion/exclusion criteria.

\section{Matching}

Principia care home residents were matched to control residents moving to a care home in the comparison areas on a range of characteristics. These included both resident characteristics, such as age, gender, health conditions and prior hospital use; and care home characteristics, such as number of beds (tables 1 and 2). Health conditions included those linked to frailty, such as incontinence, mobility problems and pressure ulcers, ${ }^{7475}$ and conditions predictive of emergency readmission, such as renal disease and metastatic cancer. ${ }^{76}$ These baseline variables were chosen for their potential ability to predict future emergency hospital use and therefore, if they differed between care home residents in Rushcliffe and the comparison areas, could be confounders.

We performed the matching separately for residential and nursing homes, using Genetic Matching, a computer intensive search algorithm that can produce more closely balanced groups than traditional methods based on the propensity score. ${ }^{77}$ Matching was done with replacement, that is, a control resident could be 
Table 1 Baseline resident characteristics after matching (figures show per cent of residents unless otherwise stated)

\begin{tabular}{|c|c|c|c|c|}
\hline & \multicolumn{2}{|c|}{ Residential care homes } & \multicolumn{2}{|c|}{ Nursing homes } \\
\hline & Principia & $\begin{array}{l}\text { Matched } \\
\text { controls }\end{array}$ & Principia & $\begin{array}{l}\text { Matched } \\
\text { controls }\end{array}$ \\
\hline Total number of residents (residencies) & 203 & 203 & 365 & 365 \\
\hline Total number of unique residents & 203 & 166 & 365 & 263 \\
\hline Median age, years (IQR) & $\begin{array}{l}88.46(83.72 \\
93.34)\end{array}$ & $\begin{array}{l}89.04(85.22 \\
92.33)\end{array}$ & $\begin{array}{l}85.63(80.80 \\
90.22)\end{array}$ & $\begin{array}{l}86.72(82.04 \\
90.13)\end{array}$ \\
\hline Male & $28.6 \%$ & $26.6 \%$ & $42.7 \%$ & $40.5 \%$ \\
\hline White & $86.7 \%$ & $85.7 \%$ & $89.9 \%$ & $84.1 \%$ \\
\hline $\begin{array}{l}\text { Charlson index, based on health conditions recorded in } 2 \text { years prior } \\
\text { to moving to the care home, mean (SD) }\end{array}$ & $1.88(1.53)$ & $1.81(1.57)$ & $2.52(1.95)$ & $2.45(1.87)$ \\
\hline $\begin{array}{l}\text { Number of conditions linked to frailty recorded in } 2 \text { years prior to } \\
\text { moving to the care home, mean (SD) }\end{array}$ & $2.03(1.66)$ & $1.89(1.56)$ & $2.19(1.58)$ & $2.03(1.40)$ \\
\hline Anxiety or depression & $18.2 \%$ & $15.8 \%$ & $15.6 \%$ & $20.5 \%$ \\
\hline Cognitive impairment & $50.2 \%$ & $48.3 \%$ & $58.1 \%$ & $54.0 \%$ \\
\hline Functional dependence* & $25.1 \%$ & $24.1 \%$ & $23.8 \%$ & $15.9 \%$ \\
\hline Fall or significant fracture & $53.2 \%$ & $49.3 \%$ & $52.1 \%$ & $46.8 \%$ \\
\hline Incontinence & $11.3 \%$ & $8.4 \%$ & $15.1 \%$ & $9.3 \%$ \\
\hline Mobility problems & $22.7 \%$ & $22.2 \%$ & $26.8 \%$ & $27.9 \%$ \\
\hline Pressure ulcers & $7.9 \%$ & $6.9 \%$ & $8.8 \%$ & $16.4 \%$ \\
\hline \multicolumn{5}{|l|}{$\begin{array}{l}\text { Other health conditions recorded in the } 2 \text { years prior to moving to the } \\
\text { care home that were considered predictive of hospital readmission }\end{array}$} \\
\hline Metastatic cancer with solid tumour & Freq $<10$ & Freq $<10$ & $7.7 \%$ & $6.0 \%$ \\
\hline Other malignant cancer & $9.4 \%$ & $9.4 \%$ & $19.5 \%$ & $15.1 \%$ \\
\hline Chronic pulmonary disease & $13.3 \%$ & $9.4 \%$ & $20.0 \%$ & $17.5 \%$ \\
\hline Congestive heart failure & $15.8 \%$ & $10.3 \%$ & $16.2 \%$ & $23.8 \%$ \\
\hline Dementia & $52.2 \%$ & $49.8 \%$ & $53.4 \%$ & $49.9 \%$ \\
\hline Diabetes with chronic complications & Freq $<10$ & Freq $<10$ & $2.7 \%$ & $2.7 \%$ \\
\hline Hemiplegia or paraplegia & Freq $<10$ & Freq $<10$ & $4.1 \%$ & $4.7 \%$ \\
\hline Moderate or severe liver disease & Freq $<10$ & Freq $<10$ & Freq $<10$ & Freq $<10$ \\
\hline Other liver disease & Freq $<10$ & Freq $<10$ & $2.7 \%$ & Freq $<10$ \\
\hline Peripheral vascular disease & Freq $<10$ & Freq $<10$ & $7.9 \%$ & $7.9 \%$ \\
\hline Renal disease & Freq $<10$ & Freq $<10$ & Freq $<10$ & Freq $<10$ \\
\hline \multicolumn{5}{|l|}{ Hospital use prior to moving to the care home, mean (SD) } \\
\hline Potentially avoidable emergency admissions in prior year & $0.45(0.68)$ & $0.41(0.66)$ & $0.51(1.03)$ & $0.57(0.93)$ \\
\hline $\begin{array}{l}\text { Potentially avoidable emergency admissions in year before prior } \\
\text { year }\end{array}$ & $0.12(0.41)$ & $0.11(0.41)$ & $0.16(0.53)$ & $0.17(0.49)$ \\
\hline Emergency admissions in prior year & $1.61(1.39)$ & $1.49(1.08)$ & $1.76(1.56)$ & $1.78(1.51)$ \\
\hline Emergency admissions in year before prior year & $0.59(1.06)$ & $0.49(0.92)$ & $0.66(1.22)$ & $0.69(1.05)$ \\
\hline A\&E attendances in prior year & $1.65(1.63)$ & $1.70(1.35)$ & $1.68(1.52)$ & $1.76(1.68)$ \\
\hline Hospital bed days in prior year & $24.29(27.32)$ & $24.70(27.38)$ & $45.78(46.63)$ & $43.99(43.37)$ \\
\hline Elective admissions in prior year & $0.24(0.50)$ & $0.17(0.43)$ & $0.43(1.19)$ & $0.37(1.17)$ \\
\hline Outpatient attendances in prior year & $3.45(4.04)$ & $2.60(4.17)$ & $4.51(7.18)$ & $3.78(5.84)$ \\
\hline
\end{tabular}

All percentages are based on number of residents (residencies). Percentages are suppressed where there was an underlying frequency of less than 10. See online supplementary file 3 for an assessment of the balance between Principia and the matched control groups.

* Functional dependence indicates a change in discharge destination from hospital to an institution providing more social and functional support than at hospital admission.

A\&E, Accident \& Emergency.

matched to more than one Principia resident. ${ }^{78}$ The similarity of the Principia and matched control groups was judged separately for residential and nursing homes using the standardised mean difference, defined as the difference in means between the Principia and control group as a proportion of the SD in the Principia group. ${ }^{78}$ If the standardised mean difference for a baseline variable is within the $\pm 10 \%$ threshold, then we considered that variable to be balanced. ${ }^{79}$

\section{Statistical approach}

We assessed the difference in hospital use between Principia and matched control residents for each care home type by fitting multivariable regression models. We did 
Table 2 Baseline care home characteristics after matching (figures show per cent of care homes unless otherwise specified)

\begin{tabular}{|c|c|c|c|c|}
\hline & \multicolumn{2}{|c|}{ Residential care homes } & \multicolumn{2}{|c|}{ Nursing homes } \\
\hline & Principia & $\begin{array}{l}\text { Matched } \\
\text { controls }\end{array}$ & Principia & $\begin{array}{l}\text { Matched } \\
\text { controls }\end{array}$ \\
\hline $\begin{array}{l}\text { Number of } \\
\text { residents } \\
\text { (residencies) }\end{array}$ & 203 & 203 & 365 & 365 \\
\hline $\begin{array}{l}\text { Number of care } \\
\text { homes }\end{array}$ & 13 & 47 & 10 & 27 \\
\hline $\begin{array}{l}\text { Number of beds } \\
\text { per care home, } \\
\text { mean (SD) }\end{array}$ & $\begin{array}{l}38.25 \\
(20.03)\end{array}$ & $\begin{array}{l}38.89 \\
(17.54)\end{array}$ & $\begin{array}{l}52.05 \\
(16.81)\end{array}$ & $\begin{array}{l}54.51 \\
(25.49)\end{array}$ \\
\hline $\begin{array}{l}\text { Care home } \\
\text { registered as } \\
\text { caring for older } \\
\text { people only }\end{array}$ & $100.0 \%$ & $100.0 \%$ & $78.4 \%$ & $78.4 \%$ \\
\hline Rural setting & $56.2 \%$ & $52.7 \%$ & $55.3 \%$ & $39.5 \%$ \\
\hline \multicolumn{5}{|l|}{$\begin{array}{l}\text { Index of Multiple } \\
\text { Deprivation (IMD) } \\
\text { quintile }\end{array}$} \\
\hline $\begin{array}{l}1 \text { (most } \\
\text { deprived) }\end{array}$ & N/A & $0 \%-5 \%$ & $\mathrm{~N} / \mathrm{A}$ & $0 \%-5 \%$ \\
\hline 2 & $N / A$ & $0 \%-5 \%$ & $N / A$ & $0 \%-5 \%$ \\
\hline 3 & $25 \%-30 \%$ & $15 \%-20 \%$ & $\mathrm{~N} / \mathrm{A}$ & $0 \%-5 \%$ \\
\hline 4 & $0 \%-5 \%$ & $25 \%-30 \%$ & $55 \%-60 \%$ & $55 \%-60 \%$ \\
\hline $\begin{array}{l}5 \text { (least } \\
\text { deprived) }\end{array}$ & $65 \%-70 \%$ & $50 \%-55 \%$ & $40 \%-45 \%$ & $40 \%-45 \%$ \\
\hline \multicolumn{5}{|l|}{$\begin{array}{l}\text { Care home } \\
\text { location (local } \\
\text { authority) }\end{array}$} \\
\hline Principia* & $100.0 \%$ & $0.0 \%$ & $100.0 \%$ & $0.0 \%$ \\
\hline Harborough & N/A & $18.7 \%$ & $\mathrm{~N} / \mathrm{A}$ & $3.0 \%$ \\
\hline Blaby & $N / A$ & $15.3 \%$ & $N / A$ & $7.4 \%$ \\
\hline Test Valley & $\mathrm{N} / \mathrm{A}$ & $8.4 \%$ & $N / A$ & $37.3 \%$ \\
\hline $\begin{array}{l}\text { South } \\
\text { Cambridgeshire }\end{array}$ & N/A & $22.2 \%$ & $\mathrm{~N} / \mathrm{A}$ & $27.1 \%$ \\
\hline Chelmsford & $\mathrm{N} / \mathrm{A}$ & $19.2 \%$ & $N / A$ & $13.2 \%$ \\
\hline Brentwood & N/A & $16.3 \%$ & $\mathrm{~N} / \mathrm{A}$ & $12.1 \%$ \\
\hline \multicolumn{5}{|c|}{$\begin{array}{l}\text { All percentages are based on number of residents (residencies). For IMD } \\
\text { quintiles, ranges are provided to ensure that the percentages are not disclosive. } \\
\text { See online supplementary file } 3 \text { for an assessment of the balance between } \\
\text { Principia and the matched control groups. } \\
\text { *Includes Rushcliffe and one care home in a neighbouring area receiving } \\
\text { Principia enhanced support. } \\
\text { N/A, not applicable. }\end{array}$} \\
\hline
\end{tabular}

this, rather than fitting a model with an interaction term to data from both residential and nursing homes, as we were interested in understanding the effect of enhanced support within each care home type's context and patient population. However, we also assessed whether there was any difference in the rate ratios between care home types by fitting a multivariable regression model to data from both residential and nursing homes, and including an interaction term between the intervention assignment and the care home type.

For each outcome, several models were explored to determine which most appropriately fitted the data. Reviewed modelling options included different model specifications (eg, Poisson, Negative Binomial) and different sets of covariates, taking into account data sparsity (see online supplementary file 2 for details of final models). All baseline characteristics presented in tables 1 and 2 were potential covariates. Where a similarly good fit was observed for different models of a given outcome, we typically opted for the model that adjusted for the largest covariate set not leading to overparametrisation.

\section{Sensitivity analyses}

We also calculated crude rates of hospital activity in residential and nursing homes across England for the period 18 January 2015 to 15 January 2017. The same inclusion/exclusion criteria were applied as detailed above, that is, new residents aged 65 or over moving to care homes caring for older people during the study period and who had an inpatient admission in the 2 years prior to moving in. Although rates in the matched control subgroups were not expected to be representative of the country as the comparison areas were chosen to be similar to Rushcliffe, by calculating crude rates of emergency hospital use for residents aged 65 or over moving to care homes across England we aimed to frame our results within the national context. National care home residents were identified using similar methods as detailed above, with the exception of using automated address cleaning software provided by Experian. ${ }^{80}$ This software assigns a standardised address format to each address that can be used to match addresses electronically; this was necessary given the size of the national data.

\section{RESULTS}

\section{Study populations}

After applying the inclusion and exclusion criteria, 203 residents moving to 13 Principia residential care homes and 365 residents moving to 10 Principia nursing homes were included in the study: see flow diagram, online supplementary file 1 . As expected, given that residential care homes do not provide in-house nursing care, Principia residential care residents had on average fewer health conditions than Principia nursing residents (eg, cancer and chronic pulmonary disease), and a lower Charlson score (1.88 vs 2.52) (table 1). They also had lower levels of hospital use prior to moving to the care home and fewer died during the study period ( $27 \%$ vs $41 \%$, table 3 ). Principia residential care residents had, however, similar levels of frailty to their nursing home counterparts, as measured by items such as the number of hospital admissions relating to falls/significant fractures prior to moving to the care home. Residential care homes were in general smaller than nursing homes (mean 38 vs 52 beds). None of the Principia care homes were located in the most deprived areas of England, as measured by the Index of Multiple Deprivation (table 2).

Following matching, in the residential subgroup, matched control residents were similar to Principia residents across most resident and care home characteristics, although the Principia residents had a consistent 
Table 3 Crude rates of secondary use (number of events per person per year)

\begin{tabular}{|c|c|c|c|c|c|c|c|c|}
\hline \multirow[b]{3}{*}{$\begin{array}{l}\text { Outcomes over the follow-up } \\
\text { period }\end{array}$} & \multicolumn{4}{|c|}{ Residential care homes } & \multicolumn{4}{|c|}{ Nursing homes } \\
\hline & \multicolumn{2}{|l|}{ Principia } & \multicolumn{2}{|c|}{ Matched controls } & \multicolumn{2}{|l|}{ Principia } & \multicolumn{2}{|c|}{ Matched controls } \\
\hline & Events & Crude rate* & Events & Crude rate* & Events & Crude rate* & Events & Crude rate* \\
\hline Total number of residencies & 203 & & 203 & & 365 & & 365 & \\
\hline Total number of unique residents & 203 & & 166 & & 365 & & 263 & \\
\hline Person-years of follow-up & 145.3 & & 139.3 & & 182.1 & & 189.6 & \\
\hline $\begin{array}{l}\text { Potentially avoidable emergency } \\
\text { admissions }\end{array}$ & 29 & 0.20 & 56 & 0.40 & 44 & 0.24 & 38 & 0.20 \\
\hline Emergency admissions & 86 & 0.59 & 129 & 0.93 & 124 & 0.68 & 100 & 0.53 \\
\hline A\&E attendances & 119 & 0.82 & 185 & 1.33 & 124 & 0.68 & 131 & 0.69 \\
\hline Hospital bed days $†$ & $5.5(15.6)$ & $0.035(0.115)$ & $5.9(12.4)$ & $0.039(0.107)$ & $3.5(8.9)$ & $0.031(0.094)$ & $3.5(10.1)$ & $0.034(0.120)$ \\
\hline Outpatient attendances & 303 & 2.09 & 204 & 1.46 & 350 & 1.92 & 394 & 2.08 \\
\hline $\begin{array}{l}\text { Deaths out of hospital (\% of all } \\
\text { deaths) }\end{array}$ & 40 & $74.1 \%$ & 38 & $69.1 \%$ & 127 & $84.1 \%$ & 138 & $88.5 \%$ \\
\hline Deaths (\% of all records) & 54 & $26.6 \%$ & 55 & $27.1 \%$ & 151 & $41.4 \%$ & 156 & $42.7 \%$ \\
\hline
\end{tabular}

pattern of slightly higher prevalence of health conditions and hospital use in the period before moving to the care home. In nursing homes, the two groups were somewhat less well balanced, especially on residents' conditions linked to frailty, but there was no pattern to the imbalance (tables 1 and 2, online supplementary file 3). There were no significant differences in mortality rates between the Principia and the matched control subgroups (online supplementary file 4).

\section{Comparisons of hospital use}

In residential care homes, Principia residents were followed up for an average of 22 months and matched control residents for 21 months. In nursing homes, Principia residents were followed for 15 months and matched control residents for 16 months.

In residential care homes, Principia residents had lower crude rates of potentially avoidable emergency admissions than matched control residents $(0.20$ vs 0.40 per person per year) (table 3 ). The adjusted rate ratio associated with receiving the enhanced support was 0.50 (95\% CI 0.30 to 0.82 ), equivalent to on average 0.20 less of these admissions per person per year among the Principia residents $(95 \%$ CI -0.28 to -0.07 ) (table 4 , online supplementary file 4 ). The Principia residential care home residents also had lower rates of emergency admissions than matched controls $(0.59$ vs 0.93 per person per year, adjusted rate ratio $0.60,95 \%$ CI 0.42 to 0.86 ), equivalent to 0.37 less emergency admissions per person per year (95\% CI -0.54 to -0.13$)$. They also had lower A\&E attendances ( 0.82 vs 1.33 per person per year, adjusted rate ratio $0.57,95 \% \mathrm{CI} 0.40$ to 0.81 ), equivalent to 0.57 less A\&E attendances per person per year $(95 \%$ CI -0.80 to -0.25$)$.

In nursing homes, there was no statistical difference in rates of emergency hospital use between the
Principia and matched control residents (tables 3 and 4, online supplementary file 4).

Across all three measures of emergency hospital use, there were differences in the adjusted rate ratios between residential and nursing homes, with the rate ratios being statistically significantly lower for residential care homes (table 4, online supplementary file 4).

There was no evidence of a difference between Principia and matched control residents in either residential or nursing homes on total hospital bed days, outpatient attendances or deaths outside hospital. There was also no evidence of a difference in rate ratios between the two care home types for any of these measures (tables 3 and 4, online supplementary file 4).

\section{Sensitivity analyses}

In the above analysis, we noticed that matched control residents of residential care homes had higher emergency hospital use than matched control residents of nursing homes, despite having lower levels of sickness (tables 1 and 3). For example, crude rates of emergency admissions in the matched control group were 0.93 per person per year in the residential care homes versus 0.53 in nursing homes. We therefore explored whether a similar pattern existed across similar care home residents in England and found that it does (table 5).

\section{DISCUSSION}

In residential care homes, Principia residents experienced fewer potentially avoidable emergency admissions, emergency admissions and A\&E attendances than matched control residents. In nursing homes, the results were inconclusive as to whether Principia residents experienced more or fewer emergency hospital activity than the matched control group. The difference in results between residential and nursing 
Table 4 Results of adjusted regression models

\begin{tabular}{|c|c|c|c|c|c|c|}
\hline \multirow[b]{2}{*}{$\begin{array}{l}\text { Outcomes over the follow-up } \\
\text { period }\end{array}$} & \multicolumn{2}{|c|}{ Relative difference } & \multicolumn{2}{|c|}{ Absolute difference } & \multirow[b]{2}{*}{$P$ value } & \multirow[b]{2}{*}{$\begin{array}{l}\text { Interaction test } \\
\text { P value* }^{*}\end{array}$} \\
\hline & $\begin{array}{l}\text { Point } \\
\text { estimate }\end{array}$ & $95 \% \mathrm{Cl}$ & $\begin{array}{l}\text { Point } \\
\text { estimate }\end{array}$ & $95 \% \mathrm{Cl}$ & & \\
\hline \multicolumn{7}{|l|}{ Residential care homes } \\
\hline $\begin{array}{l}\text { Potentially avoidable } \\
\text { admissions }\end{array}$ & 0.50 & (0.30 to 0.82 ) & -0.20 & $(-0.28$ to -0.07$)$ & 0.007 & 0.020 \\
\hline Emergency admissions & 0.60 & (0.42 to 0.86$)$ & -0.37 & $(-0.54$ to -0.13$)$ & 0.004 & 0.005 \\
\hline A\&E attendances & 0.57 & (0.40 to 0.81$)$ & -0.57 & $(-0.80$ to -0.25$)$ & 0.001 & 0.008 \\
\hline \multirow[t]{2}{*}{ Hospital bed dayst } & 0.81 & (0.43 to 1.53$)$ & -0.007 & $(-0.022$ to 0.021$)$ & 0.467 & Count: 0.858 \\
\hline & & & & & & Zero: 0.135 \\
\hline Outpatient attendances & 1.28 & (0.88 to 1.86$)$ & 0.41 & $(-0.18$ to 1.26$)$ & 0.169 & 0.266 \\
\hline Deaths outside hospital & 1.25 & (0.54 to 2.92$)$ & $17.3 \%$ & $(-31.8 \%$ to $132.7 \%)$ & 0.608 & 0.558 \\
\hline \multicolumn{7}{|l|}{ Nursing homes } \\
\hline $\begin{array}{l}\text { Potentially avoidable } \\
\text { admissions }\end{array}$ & 1.17 & (0.76 to 1.81$)$ & 0.03 & $(-0.05$ to 0.16$)$ & 0.484 & \\
\hline Emergency admissions & 1.15 & (0.85 to 1.56$)$ & 0.08 & $(-0.08$ to 0.30$)$ & 0.352 & \\
\hline A\&E attendances & 1.04 & (0.78 to 1.38$)$ & 0.03 & $(-0.15$ to 0.26$)$ & 0.806 & \\
\hline Hospital bed days & 1.07 & (0.64 to 1.80$)$ & 0.002 & $(-0.012$ to 0.027$)$ & 0.790 & \\
\hline Outpatient attendances & 0.97 & (0.71 to 1.32$)$ & -0.06 & $(-0.60$ to 0.67$)$ & 0.840 & \\
\hline Deaths outside hospital & 1.00 & (0.40 to 2.49$)$ & 0.00 & $(-53.1 \%$ to $131.9 \%)$ & 0.992 & \\
\hline
\end{tabular}

All relative differences are rate ratios, apart from deaths outside hospital and deaths, which are ORs. See online supplementary file 2 for a list of covariates each outcome was adjusted for and for model fit statistics. Absolute differences are calculated by first calculating the relative difference, then multiplying the relative difference with the crude rate in the matched control group, and then comparing the resulting rate to the crude rate.

* Interaction test of residential versus nursing homes.

tThe absolute difference in hospital bed days shows the difference in the proportion of hospital bed days out of the period residents were followed up in the study. The interaction model estimating hospital bed days is a Hurdle model and produces separate effect estimates on whether a resident is hospitalised or not ('Zero' part) and on the number of hospital bed days following hospitalisation ('Count' part).

A\&E, Accident \& Emergency.

homes was statistically significant. Before considering what these findings might imply for the impact of the enhanced support, it is necessary to acknowledge the strengths and limitations of the study.

\section{Strengths and limitations of this study}

A well-known issue with observational studies is that, in the absence of randomisation, there may be differences between the groups that could confound estimates of treatment effectiveness. Here, we compared

Table 5 National crude rates of emergency hospital use for care home residents aged 65 or over across England

\begin{tabular}{|c|c|c|}
\hline & $\begin{array}{l}\text { Residential } \\
\text { care homes }\end{array}$ & $\begin{array}{l}\text { Nursing } \\
\text { homes }\end{array}$ \\
\hline Total number of residents in England* & 66236 & 81491 \\
\hline Person-years of follow-up & 45639 & 48758 \\
\hline \multicolumn{3}{|l|}{$\begin{array}{l}\text { Crude rates (number per person per year) for } \\
\text { outcomes }\end{array}$} \\
\hline Potentially avoidable emergency admissions & 0.39 & 0.36 \\
\hline Emergency admissions & 1.04 & 0.87 \\
\hline A\&E attendances & 1.44 & 1.10 \\
\hline \multicolumn{3}{|c|}{$\begin{array}{l}\text { * Residents aged } 65 \text { or over moving to care homes caring for older } \\
\text { people during the period mid-January } 2015 \text { to mid-January } 2017 \text { in } \\
\text { England. The same inclusion/exclusion criteria were applied as in the } \\
\text { main analysis. } \\
\text { A\&E, Accident \& Emergency. }\end{array}$} \\
\hline
\end{tabular}

the hospital use of Principia care home residents with the hospital use of a retrospectively matched control group, formed of residents moving to care homes in six other local authorities in England. These areas were chosen for having similar demographic and socioeconomic characteristics to Rushcliffe, as well as similar per capita rates of emergency admissions. The matching algorithm ensured that the matched control residents had broadly similar characteristics as Principia residents at the point of moving to the care home (including age, gender, health conditions and prior hospital use) and also moved to care homes with similar characteristics. The analysis allowed for further risk adjustment to be made at the multivariable regression stage. Notwithstanding this, there may be unobserved differences that may have affected the estimated rate ratios. For example, the groups might differ in social isolation, or the areas might differ in terms of their healthcare provision. Coding practices within administrative hospital records can also vary between hospitals. ${ }^{81}$ We somewhat reduced the risk of unobserved confounding by selecting matched controls from six (rather than one) different comparison areas. Furthermore, it is reassuring that the outcomes in residential and nursing homes are different, as unobserved differences in hospital practices or coding would be expected to confound outcomes in both care home types. We were also reassured that there were no 
significant differences in mortality rates between the Principia and the matched control subgroups; as it was not expected that the Principia enhanced support would have a substantial effect on mortality, this lends further reassurance that the compared resident groups were similar.

One observation is that the matched control residents in the nursing subgroups experienced much less emergency hospital use than the national average (tables 3 and 5). Although there is no reason to expect these rates to be the same, this result could mean that nursing homes in the control group were offering particularly good care, making it more difficult to detect a significant improvement in Principia nursing homes. To investigate this possibility, we performed a sensitivity analysis removing one comparison area at a time. This indicated that no single comparison area was driving the results (results not shown).

Both the evaluation of the enhanced support and the national analysis were based on the subset of residents who moved to a care home during the study period and had a history of prior hospital use. Their rates of hospital use may differ from those of the overall care home population.

A strength of our study is that we linked administrative hospital records to CQC data and information derived from patient registration data. This resulted in a database containing the hospital histories of every care home resident in the selected areas, without the problems of non-response that can be encountered in study designs that use survey data. However, we could only identify people as living in a care home when their addresses were updated on their GP record. This happens routinely when individuals move to care homes on a permanent basis, but we are likely to have excluded residents who moved to the care home temporarily. Also, as NHAIS extracts were only available from August 2014 onwards, we could not compare the rates of hospital admission between Principia and control care homes before the intervention was introduced. Furthermore, we did not examine other aspects of quality of care, such as quality of life, resident experience or medicine management.

The list of conditions for which emergency admissions are potentially avoidable was developed by the CQC. ${ }^{6768}$ As the focus of the CQC analysis was on older people experiencing health and social care, the list was not specific to care home residents. However, from a list of commonly defined ambulatory care sensitive conditions from the literature, CQC selected those that affected older patients particularly from care home postcodes, then added additional conditions that were considered to indicate potential poor care within the community or care home (eg, fractures and pressure sores). ${ }^{68}$ Furthermore, the list captures some of the most common preventable causes of harm in care homes. ${ }^{48}$ Further research is needed to validate the appropriateness of these conditions as a marker of avoidable admissions for the care home population. In the meantime, the data presented can only be taken as an illustration of the range of health conditions for which care home residents are admitted to hospital, some of which are potentially avoidable.

For the sensitivity analysis of national rates of emergency hospital use, commercial software was used to automate the address cleaning before electronically matching addresses. Our validation work showed that this method, although correctly identifying care home residents, underestimated the number of care home residents compared with manual matching. There is, however, no reason why this would have biased the results.

Subgroup analyses such as the ones presented in this paper can sometimes produce false positives. However, using published criteria to evaluate the credibility of subgroup analyses, ${ }^{82}$ the subgroup difference here is considered very plausible. In particular, the subgroup analysis by care home type was specified a priori and was the only subgroup specified; care home type was determined at baseline; the comparison was made within, rather than between, studies; the interaction test was highly significant, suggesting a low likelihood that chance alone explained the apparent difference between residential and nursing homes; and the effect was consistent across several closely related outcomes relating to emergency hospital use.

Given the strengths and limitations described above, one plausible explanation for the difference in emergency hospital use in residential care homes is that the enhanced support reduced hospital use in residential care homes, although we could not altogether rule out confounding. The effect of enhanced support appears to be different between residential and nursing homes.

\section{Mechanisms and interpretation}

Assuming that the difference in rate ratios in emergency care between residential and nursing homes is due to a difference in impact of the enhanced support, there could be a number of contributing factors.

First, the intervention might have been applied differently in residential and nursing homes. For example, there were some differences in how the community nurse support and training operated, with residential care home staff receiving more training than nursing home staff. The training, which is not part of 'usual care' in care homes, might also have led to more regular contact between care home staff and community nurses in residential care homes, improving the quality of the relationships and helping to establish community nurses as a useful point of contact when care home staff are concerned about a resident's health, rather than relying on emergency services. ${ }^{2152}$

Second, residents of residential care homes might have been more amenable ('impactible') ${ }^{83}$ to the additional support than residents of nursing homes since, while frail, they had in general fewer health conditions 
than nursing home residents. Nursing home residents, in contrast, had higher rates of health conditions such as cancer and chronic pulmonary disease and were more often nearing their end of life. Given nursing home residents' clinical history and the shorter average time spent in the home, there may be more limited scope to reduce their hospital use.

A third possibility is that the enhanced support was more effective in residential care homes than in nursing homes even if applied in the same way. Residential care homes do not have 24 hours' access to nursing expertise as in nursing homes, and so may have benefited more from the additional support from GPs and community nurses. ${ }^{21} 34$

A fourth possibility is that what qualifies as 'usual care' may differ between residential and nursing homes. In general, it is common for a care home to have residents registered with several different general practices and for the GP 'on call', rather than a regular named GP, to visit a resident if required. ${ }^{84}$ However, it may be that nursing homes are on the whole benefitting from more regular GP contact than residential care homes. ${ }^{43} 646584$ This may be particularly true in the matched control nursing homes, which had on average lower rates of emergency hospital use than nursing homes nationally (tables 3 and 5). This could be limiting the difference between 'usual care' and the enhanced support in nursing homes and thereby affect our ability to detect a difference in Principia care homes. Furthermore, nursing home residents in general have more well-defined and preterminal conditions ${ }^{85}$ and are therefore more likely to have predicted medical pathways and more established end-of-life planning, even in the absence of the enhanced support. Staff may therefore feel more able to make decisions on whether or not to admit nursing home residents to hospital.

These last two hypotheses are supported by our observation that nationally, residential care home residents have higher rates of $\mathrm{A} \& \mathrm{E}$ attendances and emergency admission than nursing home residents, suggesting that there could be more potential to reduce emergency admissions among residents in those homes than in nursing homes. It may be that residential care home residents also often have complex healthcare needs ${ }^{4352}$ and that in the absence of clinical knowledge, health problems may not be detected and addressed as early as they could be or managed as well, ${ }^{52}$ or that staff do not feel confident to make decisions regarding their residents' health, therefore relying more on emergency services. ${ }^{213452}$ As such, the impact of additional GP and community nurse support, advice and training may be larger in residential care homes, increasing the staff's ability to proactively manage health risks and reducing their reliance on emergency services.

Several studies have pointed towards the importance of care home and NHS staff working together as partners ${ }^{3248}$ to codesign and implement concerted approaches to healthcare ${ }^{15}$ and of acknowledging care home staff's knowledge and skills. ${ }^{45}$ Nursing home staff include nurses with clinical expertise, who may feel more responsible for their residents' clinical needs than other care home staff. In nursing homes, improvement programmes may therefore require more engagement and emphasis on coproduction in order to build good working relationships and codevelop the elements of the intervention.

It is not possible to determine which of these-or other-intervention-specific or contextual factors contributed to the observed differences in emergency hospital use. A qualitative evaluation could shed light on the likelihood of and interplay between the above outlined factors.

\section{Comparison with other studies}

To our knowledge no previous studies have compared the impact of enhanced support interventions between residential and nursing homes in the way that we have. A recent evaluation of an $\mathrm{EHCH}$ vanguard programme implemented in Sutton CCG indicated that the enhanced care provided may have affected residents of nursing and residential care homes differently; however, this was not formally investigated. ${ }^{33}$ More evaluations of the type we propose are needed to increase the evidence base on how improvement programmes are affected by the differing contextual factors in residential and nursing homes. Furthermore, complementing qualitative evaluations would help identify enablers and barriers to implementation, as well as the 'active ingredients' of such programmes, thereby helping improve the replicability and scalability of successful interventions.

Compared with other patient groups, there is little robust quantitative research into care in care homes. One reason for this is that there is no readily available database identifying care home residents in administrative data such as hospital records. Encouragingly, two other research teams have recently investigated or developed methods for identifying care home residents from patient addresses. ${ }^{86} 87$ However, it is important that these data are routinely and consistently collected and easily accessible to both research teams and care providers, if we are to understand residents' healthcare needs, produce robust evaluations and ultimately improve care for this vulnerable patient group.

\section{CONCLUSIONS}

This study shows that people moving to residential care homes participating in the enhanced support experienced significantly fewer potentially avoidable emergency admissions, emergency admissions and A\&E attendances than a matched control group. However, there was no evidence that people moving to participating nursing homes experienced lower hospital use. The impact of the enhanced support appears to differ between the two types of care homes. 
It may be that improvement programmes such as the enhanced support have more potential to reduce emergency hospital use among residents in residential than nursing homes. Indeed, we observed in this study that nationally, residential care home residents tend to use more emergency hospital services than nursing home residents, even though we would expect them to be less sick, given that residential care homes do not provide in-house nursing support. There may be scope to reduce emergency admissions among nursing home residents but improvement programmes may need to be more tailored to the needs of nursing home residents and the context of providing care in that setting.

Given the ongoing policy changes in the English NHS and their emphasis on improving care in care homes, ${ }^{10-12}$ this study may inform decisions about what interventions should be implemented and/or how they should be targeted, thereby helping to support implementation of care home interventions in the future.

Acknowledgements The authors thank Liz Harris for sharing her knowledge of the intervention and local system throughout the evaluation and for reviewing an earlier draft. We also thank Richard Stratton for reviewing an earlier draft. We thank our colleagues within the Improvement Analytics Unit Arne Wolters, Martin Caunt, Creina Lilburne, Richard Brine, Caroline Gori, Carlotta Greci, Florence Starr and Georgina Farmer, as well as Mark Marshall and Sarah Blundell from the NCDR, for their input at various stages of the project.

Contributors AS and TL designed the study. FS did the data management and national analysis. SC and TL performed the subgroup analysis. TL drafted the first version of the paper. All authors revised and contributed to the paper, and read and approved the final manuscript.

Funding The authors have not declared a specific grant for this research from any funding agency in the public, commercial or not-for-profit sectors.

Competing interests SC and FS are under full employment of NHS England.

\section{Patient consent for publication Not required}

Provenance and peer review Not commissioned; externally peer reviewed.

Open access This is an open access article distributed in accordance with the Creative Commons Attribution Non Commercial (CC BY-NC 4.0) license, which permits others to distribute, remix, adapt, build upon this work noncommercially, and license their derivative works on different terms, provided the original work is properly cited, appropriate credit is given, any changes made indicated, and the use is noncommercial. See: http://creativecommons.org/licenses/by-nc/4. $0 /$.

\section{REFERENCES}

1. LaingBuisson. Care of older people: UK market report; 2017.

2. NHS. Care homes. Available: https://www.nhs.uk/conditions/ social-care-and-support-guide/care-services-equipment-andcare-homes/care-homes/ [Accessed 1 Oct 2018].

3. Baylis A, Perks-Baker S. Enhanced health in care homes Learning from experiences so far. The King's Fund 2017. Available: https://www.kingsfund.org.uk/sites/default/files/ 2017-11/Enhanced_health_care_homes_Kings_Fund_ December_2017.pdf

4. Alzheimer's Society. Fix dementia care: NHS and care homes. 2016. Available: https://www.alzheimers.org.uk/sites/default/ files/migrate/downloads/fix_dementia_care_nhs_and_care_ homes report.pdf

5. British Geriatrics Society. Fit for frailty Part 1. 2014. Available: https://www.bgs.org.uk/sites/default/files/content/resources/ files/2018-05-23/fff_full.pdf

6. Bowman C, Meyer J. Formative care: defining the purpose and clinical practice of care for the frail. J R Soc Med 2014;107:95-8.

7. National End of Life Care Intelligence Network (NEoLCIN). The role of care homes in end of life care: Briefing 2 - Place and cause of death for permanent and temporary residents of care homes. 2017. Available: http://www.endoflifecareintelligence.org.uk/resources/publications/carehomes [Accessed 1 Oct 2018].

8. Prince M, Knapp M, Guerchet M, et al. Dementia UK update (second edition). Alzheimer's Society 2014. Available: https:// www.alzheimers.org.uk/sites/default/files/migrate/downloads/ dementia_uk_update.pdf [Accessed 1 Oct 2018].

9. Boyd M, Broad JB, Kerse N, et al. Twenty-year trends in dependency in residential aged care in Auckland, New Zealand: a descriptive study. J Am Med Dir Assoc 2011;12:535-40.

10. NHS. Next steps on the five year forward view. 2017. Available: https://www.england.nhs.uk/wp-content/uploads/ 2017/03/NEXT-STEPS-ON-THE-NHS-FIVE-YEARFORWARD-VIEW.pdf [Accessed 1 Oct 2018].

11. NHS England, NHS Improvement, Care Quality Commission, et al. Delivering the Forward View : NHS planning guidance 2016/17 - 2020/21. 2016. Available: https://www.england.nhs. uk/wp-content/uploads/2015/12/planning-guid-16-17-20-21. pdf [Accessed 1 Oct2018].

12. NHS. The NHS long term plan. Available: https://www. longtermplan.nhs.uk/ [Accessed 11 Jan2019].

13. Healthwatch. What's it like to live in a care home? Findings from the Healthwatch network. 2017. Available: https://www. healthwatch.co.uk/sites/healthwatch.co.uk/files/20171117 -whats_it_like_to_live_in_a_care_home.pdf [Accessed 2 Aug 2018].

14. Care Quality Commission. The state of health care and adult social care in England 2016/17. 2017. Available: https://www. cqc.org.uk/sites/default/files/20171123_stateofcare1617 report.pdf [Accessed 15 Oct 2018].

15. Goodman C, Davies SL, Gordon AL, et al. Optimal NHS service delivery to care homes: a realist evaluation of the features and mechanisms that support effective working for the continuing care of older people in residential settings. Health Serv Deliv Res 2017;5:1-204.

16. Care Quality Commission. Time to listen in care homes. dignity and nutrition inspection programme 2012. 2013. Available: http://www.cqc.org.uk/sites/default/files/documents/ time_to_listen_-_care_homes_main_report_tag.pdf [Accessed 15 Oct 2018].

17. Bowman CE, Elford J, Dovey J, et al. Acute hospital admissions from nursing homes: some may be avoidable. Postgrad Med J 2001;77:40-2.

18. Goodman C, Gordon AL, Martin F, et al. Effective health care for older people resident in care homes: the optimal study protocol for realist review. Syst Rev 2014;3:1-7.

19. NHS. Five year forward view. 2014. Available: http://www. england.nhs.uk/wp-content/uploads/2014/10/5yfv-web.pdf

20. NHS. New care models: the framework for enhanced health in care homes. 2016. Available: https://www.england.nhs.uk/wpcontent/uploads/2016/09/ehch-framework-v2.pdf 
21. Care Quality Commission. Beyond barriers: how older people move between health and social care in England. 2018. Available: https://www.cqc.org.uk/publications/themed-work/ beyond-barriers-how-older-people-move-between-health-careengland

22. NHS Improvement. Guide to reducing long Hospital stays. 2018. Available: https://improvement.nhs.uk/documents/ 2898/Guide_to_reducing_long_hospital_stays_FINAL_v2.pdf [Accessed 1 Aug 2018].

23. Krumholz HM. Post-hospital syndrome--an acquired, transient condition of generalized risk. N Engl J Med 2013;368:100-2.

24. Smith P, Sherlaw-Johnson C, Ariti C, et al. Focus on : Hospital admissions from care homes. Quality Watch 2015. Available: https://www.health.org.uk/sites/health/files/QualityWatch_Focu sOnHospitalAdmissionsFromCareHomes.pdf [Accessed 1 Oct 2018].

25. Harrison JK, McKay IK, Grant P, et al. Appropriateness of unscheduled hospital admissions from care homes. Clin Med 2016;16:103-8.

26. Hanger HC, Fletcher V, Sidwell A. Acute medical admissions of older people from residential care facilities: are they appropriate? N Z Med J 2011:23-32.

27. Ouslander JG, Maslow K. Geriatrics and the triple aim: defining preventable hospitalizations in the long-term care population. J Am Geriatr Soc 2012;60:2313-8.

28. Ouslander JG, Berenson RA. Reducing unnecessary hospitalizations of nursing home residents. N Engl J Med 2011;365:1165-7.

29. National Audit Office. Developing new care models through NHS vanguards. National audit office 2018. Available: https:// www.nao.org.uk/report/developing-new-care-models-throughnhs-vanguards/ [Accessed 1 Aug 2018].

30. Graverholt B, Forsetlund L, Jamtvedt G. Reducing hospital admissions from nursing homes: a systematic review. $B M C$ Health Serv Res 2014;14.

31. Centre for Reviews and Dissemination. Interventions to reduce unplanned admissions from care home settings. 2014. Available: https://www.york.ac.uk/media/crd/Ev Briefing_ unplanned admissions from care homes.pdf [Accessed 1 Nov 2018].

32. Burns E, Nair S. New horizons in care home medicine. Age Ageing 2014;43:2-7.

33. Conti S, Gori C, Caunt M, et al. The impact of providing enhanced support for Sutton homes of care residents findings from the improvement analytics unit. The Health Foundation 2018. Available: https://www.health.org.uk/publications/theimpact-of-providing-enhanced-support-for-sutton-homes-ofcare-residents [Accessed 1 Oct 2018].

34. Sherlaw-Johnson C, Crump H, Curry N, et al. Transforming health care in nursing homes: an evaluation of a dedicated primary care service in outer East London. Nuffield trust 2018. Available: https://www.nuffieldtrust.org.uk/research/ transforming-health-care-in-nursing-homes-an-evaluation-of-adedicated-primary-care-service-in-outer-east-london [Accessed 30 Jul 2018].

35. Lloyd T, Wolters A, Steventon A. The impact of providing enhanced support for care home residents in Rushcliffe. 2017. Available: http://www.health.org.uk/sites/health/files/ IAURushcliffe.pdf

36. Maniatopoulos G, Hunter D, Erskine J, et al. North East Vanguards Programme : Final Evaluation Report May 2017. 2017. Available: https://www.necsu.nhs.uk/wp-content/ uploads/2018/03/NEVE-Final-Report-September-2017.pdf
37. Connolly MJ, Boyd M, Broad JB, et al. The aged residential care healthcare Utilization Study (ARCHUS): a multidisciplinary, cluster randomized controlled trial designed to reduce acute avoidable hospitalizations from long-term care facilities. J Am Med Dir Assoc 2015;16:49-55.

38. Kuo YF, Raji MA, Goodwin JS. Association between proportion of provider clinical effort in nursing homes and potentially avoidable hospitalizations and medical costs of nursing home residents. J Am Geriatr Soc 2013;61:1750-7.

39. Marshall M, de Silva D, Cruickshank L, et al. What we know about designing an effective improvement intervention (but too often fail to put into practice). BMJ Qual Saf 2017;26:578-82.

40. Hullick C, Conway J, Higgins I, et al. Emergency department transfers and hospital admissions from residential aged care facilities: a controlled pre-post design study. BMC Geriatr 2016;16:1-10.

41. Ouslander JG, Lamb G, Tappen R, et al. Interventions to reduce hospitalizations from nursing homes: evaluation of the interact II collaborative quality improvement project. J Am Geriatr Soc 2011;59:745-53.

42. Winstanley L, Brennan W. Advanced practice and support in prescribing and medicine management for care homes. J Care Serv Manag 2007;1:233-44.

43. Evans G, Bch BM. Factors influencing emergency hospital admissions from nursing and residential homes: positive results from a practice-based audit. J Eval Clin Pract 2011;17:1045-9.

44. National Institute for Health Research. NIHR Dissemination Centre. Advancing care - Research with care homesthemed review. 2017. Available: https://www.dc.nihr.ac.uk/themedreviews/care-home-research.htm

45. Davies SL, Goodman C, Bunn F, et al. A systematic review of integrated working between care homes and health care services. BMC Health Serv Res 2011;11.

46. Hutchinson AF, Parikh S, Tacey M, et al. A longitudinal cohort study evaluating the impact of a geriatrician-led residential care outreach service on acute healthcare utilisation. Age Ageing 2015;44:365-70.

47. Connolly MJ, Broad JB, Boyd M, et al. The 'Big Five'. Hypothesis generation: a multidisciplinary intervention package reduces disease-specific hospitalisations from long-term care: a post hoc analysis of the ARCHUS clusterrandomised controlled trial. Age Ageing 2016;45:415-20.

48. Marshall M, Pfeifer N, de Silva D, et al. An evaluation of a safety improvement intervention in care homes in England: a participatory qualitative study. J R Soc Med 2018;111:414-21.

49. Malhotra G, Somervill M. Reducing unscheduled emergency hospital admissions from care settings - a learning and development perspective. 2014. Available: https://bucks. collections.crest.ac.uk/17368/1/17368_Reducing_unscheduled_ emergency_hospital_admissions_final_report_April_2014.pdf

50. Banerjee A, James R, McGregor M, et al. Nursing home physicians discuss caring for elderly residents: an exploratory study. Can J Aging 2018;37:133-44.

51. Evans S, Means R, Powell J, et al. Making care homes part of the community? An evaluation of the Gloucestershire partnerships for older people project. Qual Ageing Older Adults 2013;14:66-74.

52. Wild D, Nelson SJ, Szczepura A. Providing nursing support within residential care homes. Joseph Rowntree Foundation Published Online First: 2008. Available: http://eprints.uwe.ac. uk/12744 [Accessed 1 Dec 2018].

53. Ouslander JG, Bonner A, Herndon L, et al. The interventions to reduce acute care transfers (INTERACT) quality 
improvement program: an overview for medical directors and primary care clinicians in long term care. J Am Med Dir Assoc 2014;15:162-70.

54. Frey R, Boyd M, Robinson J, et al. The supportive hospice and aged residential exchange (SHARe) programme in New Zealand. Nurse Educ Pract 2017;25:80-8.

55. Brownhill KM. Training in care homes to reduce avoidable harm. 2013. Available: https://www.nursingtimes.net/Journals/ 2013/10/25/p/t/r/Training-in-care-homes-to-reduce-avoidableharm_301013.pdf [Accessed 1 Dec 2018].

56. Garden G, Green S, Pieniak S, et al. The Bromhead care Home service: the impact of A service for care home residents with dementia on hospital admission and dying in preferred place of care. Clin Med 2016;16:114-8.

57. Hockley J, Watson J, Oxenham D, et al. The integrated implementation of two end-of-life care tools in nursing care homes in the UK : an in-depth evaluation 2010;24:828-38.

58. Bowman C, Whistler J, Ellerby M. A national census of care home residents. Age Ageing 2004;33:561-6.

59. Challis D, Mozley CG, Sutcliffe C, et al. Dependency in older people recently admitted to care homes. Age Ageing 2000;29:255-60.

60. Forder J, Fernandez JL. Length of stay in care homes. Report commissioned by Bupa Care Services, PSSRU Discussion Paper 2769. Canterbury: PSSRU Published Online First, 2011.

61. Barber ND, Alldred DP, Raynor DK, et al. Care homes' use of medicines study: prevalence, causes and potential harm of medication errors in care homes for older people. Qual Saf Health Care 2009;18:341-6.

62. Hancock J, Matthews J, Ukoumunne OC, et al. Variation in ambulance call rates for care homes in Torbay, UK. Health Soc Care Community 2017;25:932-7.

63. Smith P, Sherlaw-Johnson C, Ariti C, et al. Quality Watch Focus on : Hospital admissions from care homes, 2015. Available: https://www.health.org.uk/sites/default/files/ QualityWatch_FocusOnHospitalAdmissionsFromCareHomes_ appendices.pdf

64. Rothera I, Jones R, Harwood R, et al. General practitioner contacts with older residents I $\mathrm{N}$ nursing and residential homes 2009;4788.

65. Glendinning C, Jacobs S, Alborz A, et al. A survey of access to medical services in nursing and residential homes in England. Br J Gen Pract 2002;52:545-8.

66. Lloyd T, Steventon A. Statistical Analysis Protocol for an evaluation of providing enhanced support for care home residents in Rushcliffe. The Health Foundation Published Online First: 2016. Available: https://www.health.org.uk/ publications/the-impact-of-providing-enhanced-support-forcare-home-residents-in-rushcliffe [Accessed 20 Jan 2019].

67. Care Quality Commission. The state of health care and adult social care in England in 2012/13. 2013. Available: https:// www.cqc.org.uk/sites/default/files/documents/cqc_soc_report_ 2013_lores2.pdf [Accessed 1 Sep 2016].

68. Care Quality Commission. The state of health care and adult social care in England in 2012/13. Technical Annex 1: avoidable admissions. 2013. Available: https://www.cqc. org.uk/sites/default/files/documents/state_of_care_annex1. pdf[Accessed 1 Oct 2018].

69. Steventon A, Grieve R, Sekhon JS. A comparison of alternative strategies for choosing control populations in observational studies. Health Serv Outcomes Res Methodol 2015;15:157-81.
70. Lloyd T, Wolters A, Steventon A. Technical appendix : The impact of providing enhanced support for care home residents in Rushcliffe. The Health Foundation 2017. Available: https:// www.health.org.uk/sites/health/files/IAURushcliffeTA.pdf

71. Office for National Statistics. Methods for national statistics 2001 area classification for health areas. 2001. Available: https://webarchive.nationalarchives.gov.uk/20160128205413/ http://www.ons.gov.uk/ons/guide-method/geography/products/ area-classifications/ns-area-classifications/ns-2001-areaclassifications/methodology-and-variables/health-areas/index. html [Accessed 1 Nov 2018].

72. Office for National Statistics. Methodology note for the 2011 area classification for local authorities. 2015. Available: https://www.ons.gov.uk/methodology/geography/ geographicalproducts/areaclassifications/2011areaclassifi cations/methodologyandvariables [Accessed 1 Nov 2018].

73. Care Quality Commission. Care quality Commission website. Available: http://www.cqc.org.uk [Accessed 18 Sep 2017].

74. Soong J, Poots AJ, Scott S, et al. Quantifying the prevalence of frailty in English hospitals. BMJ Open 2015;5:e008456.

75. Soong J, Poots AJ, Scott S, et al. Developing and validating a risk prediction model for acute care based on frailty syndromes. BMJ Open 2015;5:e008457.

76. Billings J, Blunt I, Steventon A, et al. Development of a predictive model to identify inpatients at risk of readmission within 30 days of discharge (PARR-30). BMJ Open 2012;2:e001667.

77. Diamond A, Sekhon JS. Genetic matching for estimating causal effects: a general multivariate matching method for achieving balance in observational studies. Rev Econ Stat 2013;95:932-45.

78. Stuart EA. Matching methods for causal inference: a review and a look forward. Stat Sci 2010;25:1-21.

79. Normand ST, Landrum MB, Guadagnoli E, et al. Validating recommendations for coronary angiography following acute myocardial infarction in the elderly: a matched analysis using propensity scores. J Clin Epidemiol 2001;54:387-98.

80. Experian. Experian JukeBox. Available: https://www. digitalmarketplace.service.gov.uk/g-cloud/services/ 115957991094393 [Accessed 12 Nov 2018].

81. Bottle A, Aylin P. Comorbidity scores for administrative data benefited from adaptation to local coding and diagnostic practices. J Clin Epidemiol 2011;64:1426-33.

82. Sun X, Briel M, Walter SD, et al. Is a subgroup effect believable? updating criteria to evaluate the credibility of subgroup analyses. BMJ 2010;340:c117.

83. Lewis GH. "Impactibility models": identifying the subgroup of high-risk patients most amenable to hospital-avoidance programs. Milbank Q 2010;88:240-55.

84. Donald IP, Gladman J, Conroy S, et al. Care home medicine in the UK--in from the cold. Age Ageing 2008;37:618-20.

85 . Waldrop DP, Kusmaul N. The living-dying interval in nursing home-based end-of-life care: family caregivers' experiences. $J$ Gerontol Soc Work 2011;54:768-87.

86. Housley G, Lewis S, Usman A, et al. Accurate identification of hospital admissions from care homes; development and validation of an automated algorithm. Age Ageing 2018;47:387-91.

87 Burton JK, Marwick CA, Galloway J, et al. Identifying carehome residents in routine healthcare datasets: a diagnostic test accuracy study of five methods. Age Ageing 2019;48:114-21. 